\title{
OPEN Luciferase gene of a Caribbean fireworm (Syllidae) from Puerto Rico
}

Received: 10 June 2019

Accepted: 27 August 2019

Published online: 10 September 2019
Yasuo Mitani ${ }^{1}$, Rie Yasuno ${ }^{2}$, Ryo Futahashi $i^{3}$, Todd H. Oakley ${ }^{4}$ \& Yoshihiro Ohmiya ${ }^{2,5}$

The fireworms Odontosyllis spp. are globally distributed and well-known for their characteristic and fascinating mating behavior, with secreted mucus emitting bluish-green light. However, knowledge about the molecules involved in the light emission are still scarce. The fireworms are believed to emit light with a luciferin-luciferase reaction, but biochemical evidence of the luciferase is established for only one species living in Japan and no information is available for its luciferin structure. In this study, we identified a luciferase gene from a related Puerto Rican fireworm. We identified eight luciferaselike genes in this Puerto Rican fireworm, finding amino acid identities between Japanese and Puerto Rican luciferase-like genes to be less than $60 \%$. We confirmed cross reactivity of extracts of the Japanese fireworm luciferin with a recombinant Puerto Rican luciferase (PR1). The emission spectrum of recombinant PR1 was similar to the crude extract of the native luciferase, suggesting that PR1 is a functional luciferase of this Puerto Rican fireworm. Our results indicate that the molecular mechanism of luminescence is widely conserved among fireworms.

A wide variety of luminous animals are distributed on the earth. Some of them are terrestrial, many are marine, while only one species is known from fresh water ${ }^{1,2}$. Since the first cloning of a luciferase gene involved in light emission from the firefly Photinus pyralis ${ }^{3}$, a diversity of luciferase genes has been reported, mainly from terrestrial organisms $s^{2,4}$. While terrestrial beetles basically use the same light emission system with D-luciferin as a substrate among different families, luminous marine animals use various luciferins including coelenterazine, Cypridinid luciferin, and dinoflagellate luciferin ${ }^{2,5}$.

The fireworms Odontosyllis spp., including O. enopla, O. phosphorea, O. undecimdonta, O. octodentata, and O. luminosa, are distributed sporadically in locations around the world including the Caribbean Sea, West Coast of the United States, and Japan ${ }^{6-11}$. Despite many observations of their characteristic mating behavior, the molecular mechanisms underlying light emission is not well understood ${ }^{1,2}$. Luciferin structure has not been determined although more than 50 years ago Shimomura et al. partially purified luciferin and luciferase from more than 50,000 individuals of $O$. enopla ${ }^{12}$.

Recently, we identified a fireworm luciferase gene using unpurified luminous mucus from the Japanese species, Odontosyllis undecimdonta ${ }^{13,14}$. This luciferase gene was independently identified by another group using protein purification procedures ${ }^{15}$. The recombinant luciferase protein produced the same characteristic bluish-green emission peak as the wild fireworms ${ }^{14,15}$. It should be noted that the fireworm luciferase gene has an evolutionarily different origin from other known luciferase genes because the fireworm system did not show any cross reactivity to known systems including coelenterazine and Cypridinid luciferin ${ }^{14}$. In a third study, transcriptome analyses of the Bermuda fireworm O. enopla identified luciferase-like genes ${ }^{16}$, although its biochemical function has not been confirmed.

In this study, we focused on a fireworm from Puerto Rico. A species living in Puerto Rico was originally described as O. octodentata ${ }^{17}$ with behavior similar to O. enopla ${ }^{18}$. Although we have not determined the species in detail, we confirmed the cross reaction between the recombinant luciferase of Japanese fireworm and the ethanol extract of a Puerto Rican fireworm which probably contains fireworm luciferin. RNA sequencing (RNA-Seq) and subsequent analyses identified 8 possible luciferase paralogous genes (PR1-PR8), among which PR1 shows

${ }^{1}$ Bioproduction Research Institute, National Institute of Advanced Industrial Science and Technology (AIST), Sapporo, 062-8517, Japan. ${ }^{2}$ Biomedical Research Institute, AIST, Tsukuba, 305-8566, Japan. ${ }^{3}$ Bioproduction Research Institute, AIST, Tsukuba, 305-8566, Japan. "Marine Science Institute, University of California, Santa Barbara, CA, 93106, USA. ${ }^{5}$ DAILAB, Biomedical Research Institute, AIST, Tsukuba, 305-8566, Japan. Correspondence and requests for materials should be addressed toY.M. (email: mitani-y@aist.go.jp) 

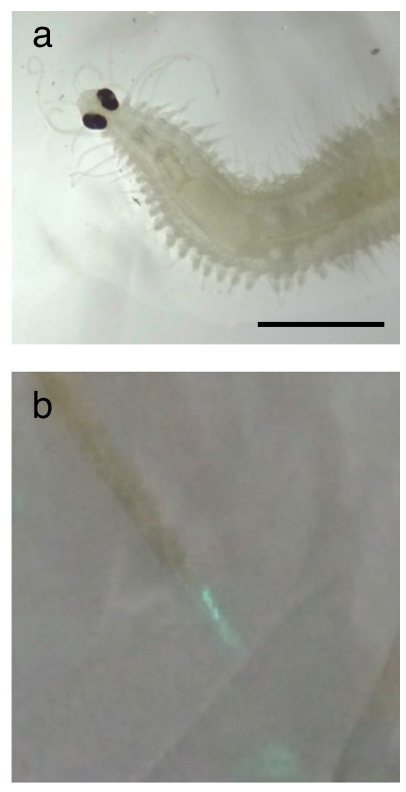

C

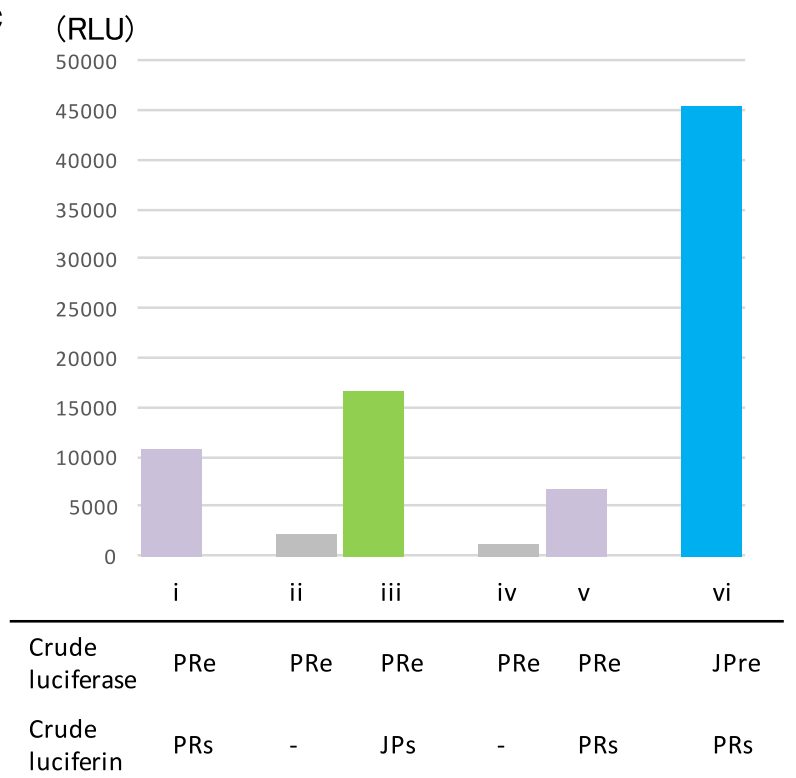

Figure 1. The Puerto Rican fireworm. (a) Bright field image of anterior part. (b) Luminous mucus from a worm that was pressed on paper. The bluish-green color appeared similar to that observed in their natural secretion during the mating behavior on the sea surface. Scale bar $=2 \mathrm{~mm}$. (c) i to $\mathrm{v}$ are a series of assays using different combination of substrate extract (PRs and JPs) using the native PRe. A $10 \mu \mathrm{L}$ of PRe was measured in $100 \mu \mathrm{L}$ RB in total (i) and left for 3 hours (ii). Then, $1 \mu \mathrm{L}$ JPs was added to this solution to check the cross reaction (iii). The activity went down to almost background level after 1 hour of the reaction (iv) and $10 \mu \mathrm{L}$ PRs was added to the mixture (v). The activity using $1 \mu \mathrm{L}$ JPre and $10 \mu \mathrm{L}$ PRs is shown in (vi).

the highest expression level. The recombinant PR1 exhibited light emitting activity in the presence of crude luciferin extract from the Japanese species. These data strongly suggested that the Japanese O. undecimdonta and the Puerto Rican species share molecular mechanisms of bioluminescence through luciferin-luciferase (LL) reaction.

\section{Results and Discussion}

Collection of the fireworm in Caribbean Sea and the LL reaction. We collected the fireworm in the Caribbean Sea, off Puerto Rico (Fig. 1a). The fireworms came to the sea surface 30 to 40 min after sunset and disappeared suddenly approximately $30 \mathrm{~min}$ after the appearance of the first visible displays, as described previously ${ }^{18}$. Their appearance peaked a couple of days after the full moon, when more than one hundred females were observed to make luminous circles. Although it was not difficult to collect them, we could not keep them alive for long periods, even in a sea table with fresh seawater flowing. After they were collected, they did not emit light even after strong stimulation; however, when they were pressed against a paper towel, a similar bluish-green light as observed on the sea surface was confirmed (Fig. 1b). This feature was different from the Japanese species because the they emit strong light when stimulated by a needle tip ${ }^{14}$. This is probably because the Caribbean individuals already secreted most of their luciferase and luciferin outside the body as a mating signal.

To conduct cross-reactivity tests, a single specimen of the Caribbean fireworm was crushed to obtain crude luciferase extract (PRe) while another specimen was soaked in ethanol to obtain crude luciferin (PRs). We used some animals for the cross reaction tests, but it was difficult to obtain clear numerical data because their activities were different from worm to worm due to the residual level of luciferase and luciferin in the body. Thus, we presented typical cross reaction data in Fig. 1. The luminous activity of the luciferase extract was confirmed visually just after crushing (Fig. 1c,i). This extract was left in a refrigerator for 3 hours to consume the luciferin (Fig. 1c,ii). The addition of the crude luciferin obtained from O. undecimdonta (JPs) recovered the luminescent activity (Fig. 1c,iii). Then, this solution was left in a refrigerator for 1 hour to exhaust the added luciferin (Fig. 1c,iv). The addition of PRs recovered the luminescent activity (Fig. 1c,v). Finally, the light emission activity was confirmed for the mixture of recombinant luciferase of the Japanese fireworm O. undecimdonta (JPre) and PRs (Fig. 1c,vi). Thus, cross-reactions between these two species were confirmed. These results suggested that the light emission mechanisms underlining these two different fireworms are the same, although we were not able to obtain quantitative data due to difficulties of collecting enough active animals.

Luciferase homolog of a fireworm from Puerto Rico. To obtain the luciferase genes, we performed RNA-Seq analysis using a single individual of Puerto Rican fireworm to exclude genetic diversity derived from polymorphism. After manual assembly, we identified 8 possible paralogous genes (PR1-PR8) with significant sequence similarity to Japanese and Bermuda fireworm luciferase genes (Fig. 2a). We numbered the genes in descending order of expression level with PR1 as the gene with the highest expression (Fig. 2b). From the molecular phylogenetic tree, three paralogous genes from the Japanese fireworm luciferase formed a single clade with the Puerto Rican fireworm luciferase PR2 and Bermuda fireworm luciferase BM1 together forming a sister clade. This 
a

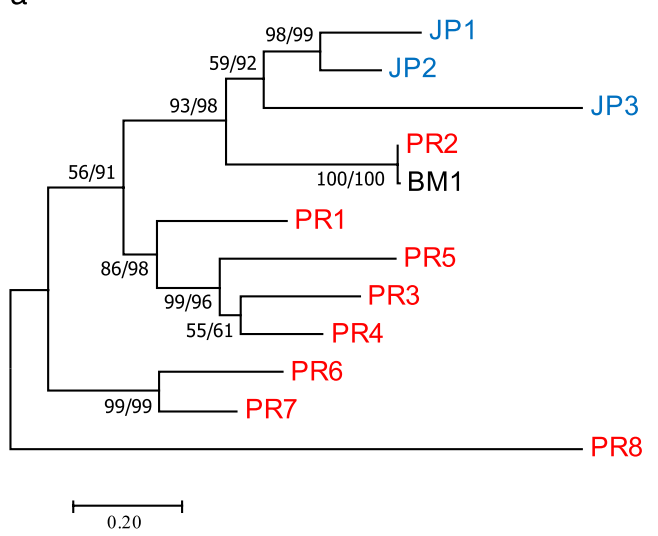

b

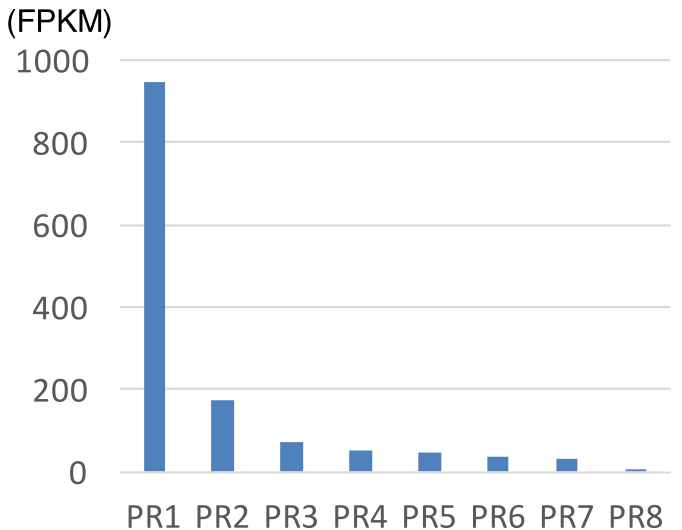

Figure 2. Molecular phylogeny and expression analysis of the Caribbean fireworm luciferase paralogs. (a) Molecular phylogenetic analysis of fireworm luciferases. A maximum likelihood phylogeny is shown, while neighbor-joining phylogeny exhibit the same topologies. Statistical supporting values are indicated on each node in the order of (bootstrap value of maximum likelihood)/(bootstrap value of neighbor-joining). (b) Relative expression level of eight luciferase-like gene in whole body of single individual calculated based on RNA-Seq analysis.

\begin{tabular}{|l|l|l|l|}
\hline & Identities & Positives & Gaps \\
\hline JP1 vs PR1 & $184 / 330(56 \%)$ & $228 / 330(69 \%)$ & $3 / 330(0.01 \%)$ \\
\hline
\end{tabular}

Table 1. Percent of identities, positives, and gaps between Japanese and Puerto Rican fireworm luciferase homologues. The number of identical amino acid residues and those with similar properties are shown as Identities and Positives, respectively.

molecular phylogenetic tree indicates that the luciferase gene duplication occurred independently in Japanese and Puerto Rican fireworms. The identity of amino acids between Japanese fireworm luciferase and Puerto Rican fireworm luciferase was less than $60 \%$ (Table 1), but the positions of 10 cysteine residues in all luciferase-like genes were conserved (Fig. 3). The Bermuda fireworm luciferase-like gene (BM1) was almost identical to PR2 with only a single amino acid substitution ( $99 \%$ identities). The high similarity of these genes suggests our Puerto Rican species is very similar or the same species as that analyzed previously from Bermuda. Although several luciferase-like paralogs were reported in the Bermuda fireworm ${ }^{16}$, there was no biochemical data of their activity as luciferase. All these luciferase-like proteins contained probable secretion signal peptides at each N-terminus (Fig. 3). As shown for Cypridina luciferase $\mathrm{e}^{19,20}$, at least one $N$-glycosylation motif characteristic of secreted proteins was found in 10 genes of 12 fireworm luciferase-like genes except PR6 and PR8 (Fig. 3, boxes).

Recombinant PR1 protein expression and its secretion property. In order to clarify the function of a Puerto Rican fireworm luciferase-like gene, we synthesized recombinant protein of PR1 which showed the highest expression level among Puerto Rican luciferase-like genes in Fig. 2. We produced recombinant PR1 by mammalian expression systems using COS1 and HEK293 cells. Luciferase activity was measured separately for supernatant of culture media (Fig. 4a, sup) and whole cell lysate (Fig. 4a, lys) after collection of the cells by centrifugation, because recombinant protein was expected to be secreted into the culture media. The recombinant protein exhibited significant light emitting activity for both supernatant and lysate fractions compared to negative control (Fig. 4a), and the ratio of the secretion fraction was higher than that of Japanese fireworm luciferase JP1 (Table 2) ${ }^{14}$. Importantly, like the Japanese fireworm luciferase ${ }^{14}$, the emission spectrum of recombinant PR1 was similar to the native luciferase crude extract with a possible peak around 510-530 nm (Fig. 4b), suggesting that PR1 is a functional luciferase gene. Improvement of recombinant PR1 protein production is necessary to obtain a clear emission spectrum to clarify its emission peak. Unfortunately, we were not able to obtain the emission spectrum using native luciferin extract from the Caribbean species due to low amount of samples.

\section{Methods}

Animal collection. Fireworms were collected in La Parguera (17.95N, 67.05W), Puerto Rico on July. 22-29, 2016. The fireworm length ranged from 5 to $30 \mathrm{~mm}$. Animals were kept frozen for a long-term storage or soaked in RNAlater (Thermo Fisher Scientific) solution and kept frozen for RNA extraction.

LL reaction. Fifty worms of the Japanese species were put into $1.5 \mathrm{~mL}$ of $99.5 \%$ ethanol, and the supernatant after short centrifugation was used as the crude luciferin solution (JPs). A single specimen of the Caribbean species was crushed in $100 \mu \mathrm{L}$ of the reaction buffer (RB) containing $50 \mathrm{mM}$ Tris- $\mathrm{HCl}(\mathrm{pH} 7.5), 300 \mathrm{mM} \mathrm{NaCl}$, and $20 \mathrm{mM} \mathrm{MgCl}_{2}$ and the supernatant collected after centrifugation at $20,000 \times \mathrm{g}$ for $10 \mathrm{~min}$ was used as a crude 


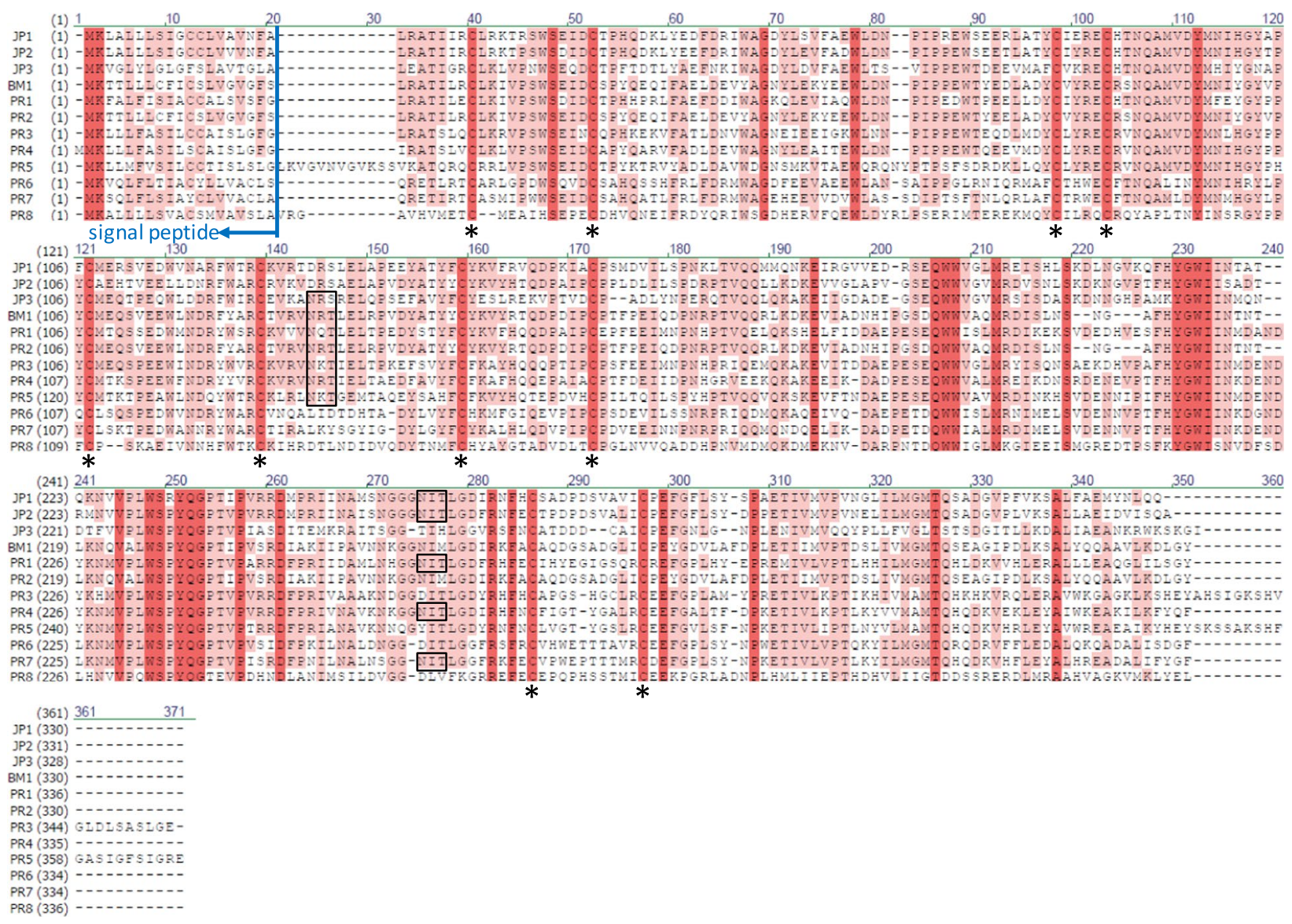

Figure 3. Comparison of amino acid sequences among fireworm luciferase-like genes. JP, BM, and PR mean Japanese O. undecimdonta (Mitani et al. ${ }^{14}$ ), Bermuda O. enopla (Brugler et al. ${ }^{16}$ ), and Puerto Rican (this study) genes, respectively. Identical or conserved amino acid residues are shaded by red and pink, respectively. $N$ terminal secretion signal sequence is indicated by arrows. $N$-glycosylation motifs are indicated by boxes. Conserved cysteine residues are indicated by asterisks.

a

(RLU)

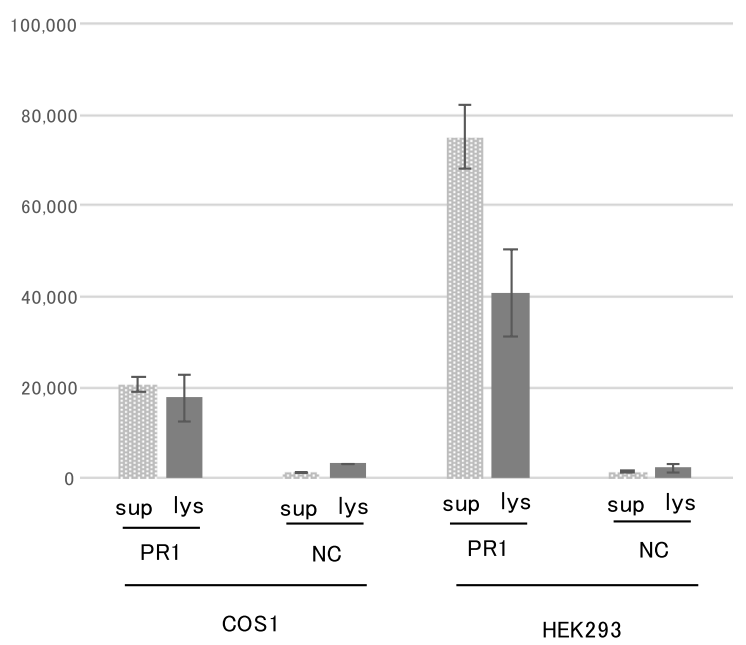

b

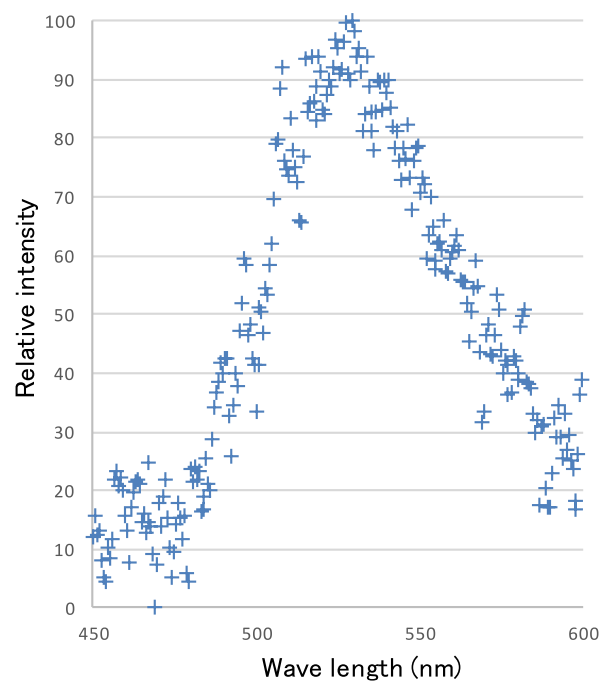

Figure 4. Recombinant luciferase expression using mammalian cells COS1 and HEK293. (a) Expression vector containing luciferase gene PR1 or empty vector as negative control (NC) was expressed and their activities were monitored. In each case, supernatant (sup) and lysate (lys) were analyzed to detect secretion and cytosolic recombinant protein, respectively. (b) Spectrum analysis of a mixture of recombinant PR1 protein and crude luciferin extract. 


\begin{tabular}{|l|l|l|}
\hline Host cell & Clone & Secretion rate (Std. dv.)/\% \\
\hline \multirow{2}{*}{ COS1 } & JP1 & $0.918(0.238)$ \\
\cline { 2 - 3 } & PR1 & $41.7(9.54)$ \\
\hline \multirow{2}{*}{ HEK293 } & JP1 & $18.4(3.09)$ \\
\cline { 2 - 3 } & PR1 & $33.9(4.14)$ \\
\hline
\end{tabular}

Table 2. Secretion rate of the recombinant luciferases. Estimated secretion rate is shown with standard deviation (std. dv.) of three independent experiments. COS1 and HEK293 were used as host cells and JP1 and PR1 were expressed.

luciferase solution (PRe) while another specimen was soaked in $100 \mu \mathrm{L}$ of ethanol and the supernatant was used as a crude luciferin extract (PRs). The recombinant luciferase for O. undecimdonta (JPre) was described previously $^{14}$. In the light emission activity assays, normally $1 \mu \mathrm{L}$ JPs, $1 \mu \mathrm{L}$ JPre, $10 \mu \mathrm{L}$ PRe, and $10 \mu \mathrm{L}$ PRs were used with an appropriate combination in $100 \mu \mathrm{L}$ RB in total. The activity was monitored using luminometer, Phelios AB-2350 (ATTO) and recorded as relative light unit (RLU) for $10 \mathrm{~s}$ accumulation of the measurement. Emission spectrum was measured using a high sensitivity CCD spectrophotometer, AB-1850S (ATTO).

RNA-Seq and gene analysis. Total RNA was extracted from one whole individual using Maxwell 16 LEV Simply RNA Tissue kit (Promega). RNA-Seq analysis was performed as described previously ${ }^{14,21}$. cDNA libraries were constructed using TruSeq RNA Sample Preparation Kits v2 (Illumina) and sequenced by MiSeq (Illumina). The raw reads were subjected to de novo assembly by using Trinity ${ }^{22}$ implemented in the MASER pipeline ${ }^{23}$. After automatic assembling, we checked and manually corrected the putative luciferase sequences as reported previously $^{24}$. After manual assembly, sequence read mapping was performed using the BWA-mem software ${ }^{25}$ implemented in the MASER pipeline, whereby the transcript expression levels were estimated to calculate the fragments per kilobase of exon per million (FPKM) values. Signal peptide sequences were predicted by using SignalP ${ }^{26}$. Multiple alignment was performed using ClustalW (DNA Data Bank of Japan). Protein similarity was estimated using BlastP program (NCBI) to find identical and similar character amino acid sequences. To construct the molecular phylogeny of fireworm luciferase genes, deduced amino-acid sequences were aligned using the Clustal $\mathrm{W}$ program implemented in MEGA ${ }^{27}$. Molecular phylogenetic analyses were conducted by the neighbor-joining method and the maximum-likelihood method using MEGA7. Bootstrap values for neighbor-joining and maximum likelihood phylogenies were obtained by 1000 resampling. Maximum Composite Likelihood model and Tamura Nei model were used for neighbor-joining and maximum likelihood analysis, respectively ${ }^{28}$. Bootstrap values for neighbor-joining and maximum likelihood phylogenies were obtained by 1000 bootstrap replications.

Recombinant protein expression in mammalian cells. Gene sequence coding PR1 optimized to human codon usage was synthesized and inserted into a pcDNA3.1- vector by an outsourcing company (Genscript). COS1 cells were cultured in Dulbecco's modified Eagle's medium (DMEM, Wako) supplemented with $10 \%$ fetal bovine serum (FBS) at $37^{\circ} \mathrm{C}$ in a humidified incubator exposed to $5 \% \mathrm{CO}_{2}$. COS 1 cells were transfected with expression plasmids using Lipofectamine 3000 (Invitrogen). On the following day, the culture medium was replaced with serum-free DMEM. The culture medium was collected $24 \mathrm{~h}$ after medium exchange and used as the supernatant fraction (sup). Cells were lysed with $10 \mathrm{mM}$ Tris- $\mathrm{HCl}$ ( $\mathrm{pH}$ 7.4) using sonication. The lysate was centrifuged at $20,000 \times \mathrm{g}$ for $5 \mathrm{~min}$, and the resulting supernatant was used as the cell extract fraction (lys). The activity of recombinant PR1 in each fraction was measured by adding $\mathrm{NaCl}$ and $\mathrm{MgCl}_{2}$ solutions to a final concentration of $300 \mathrm{mM}$ and $20 \mathrm{mM}$ each, and adding crude luciferin extract obtained from $O$. undecimdonta ${ }^{14}$. The luminescence of the mixture was immediately measured using a Phelios AB-2350 luminometer (ATTO). Secretion ratio was determined as the activity ratio of sup to total (sup plus lys) activity.

\section{References}

1. Harvey, E. N. Bioluminescence. Academic Press, New York (1952).

2. Shimomura, O. Bioluminescence: Chemical principals and methods. World Scientific (2006)

3. de Wet, J. R., Wood, K. V., Helinski, D. R. \& DeLuca, M. Cloning of firefly luciferase cDNA and the expression of active luciferase in Escherichia coli. Proc. Natl. Acad. Sci. USA 82, 7870-7873 (1985).

4. Viviani, V. R. The origin, diversity, and structure function relationships of insect luciferases. Cell. Mol. Life Sci. 59, 1833-1850 (2002).

5. Widder, E. A. Bioluminescence in the ocean: origins of biological, chemical, and ecological diversity. Science 328, 704-708 (2010).

6. Galloway, T. W. \& Welch, P. S. Studies on a phosphorescent Bermudan annelid, Odontosyllis enopla Verrill. Trans. Am. Micosc. Soc. 30, 13-39 (1911)

7. Fischer, A. \& Fisher, U. On the life-style and life-cycle of the luminous polychaete Odontosyllis enopla (Annelida: Polychaeta). Inv. Biol. 114, 236-247 (1995).

8. Markert, R. E., Markert, B. J. \& Vertrees, N. J. Lunar periodicity in spawning and luminescence in Odontosyllis enopla. Ecology. 42, 414-415 (1961).

9. Tsuji, F. I. \& Hill, E. Repetitive cycles of bioluminescence and spawning in the polychaete, Odontosyllis phosphorea. Biol. Bull. 165, 444-449 (1983)

10. Imajima, M. \& Hartman, O. The polychaetous annelids of Japan. Allan Hancock Found. Pub. Los Angeles, http://digitallibrary.usc. edu/cdm/ref/collection/p15799coll82/id/18494 (1964).

11. Gaston, G. R. \& Hall, J. Lunar periodicity and bioluminescence of swarming Odontosyllis luminosa (Polychaeta: Syllidae) in Belize. Gulf Carib. Res. 12, 47-51 (2000).

12. Shimomura, O., Johnson, F. H. \& Saiga, Y. Partial purification and properties of the Odontosyllis luminescence system. J. Cell. Phys. 61, 275-292 (1963).

13. Ohmiya, Y., Mitani, Y. \& Yasuno, R. Light-emitting enzyme protein. Patent Application WO/2017/155036 (2017).

14. Mitani, Y. et al. Novel gene encoding a unique luciferase from the fireworm Odontosyllis undecimdonta. Sci. Rep. 8, 12789 (2018). 
15. Schultz, D. T. et al. Luciferase of the Japanese syllid polychaete Odontosyllis undecimdonta. Biochem. Biophys. Res. Commun. 502, 318-323 (2018).

16. Brugler, M. R., Aguado, M. T., Tessler, M. \& Siddall, M. E. The transcriptome of Bermuda fireworm Odontosyllis enopla (Annelida: Syllidae): A unique luciferase gene family and putative epitoky-related genes. PLoS ONE 13(8), e0200944 (2018).

17. Treadwell, A. L. Polychaetous annelids from Florida, Porto Rico, Bermuda and the Bahamas. Carnegie Institute of Washington Publication. 251, 255-272 (1917)

18. Erdman, D. S. Lunar periodicity in the swarming of luminescent worms, Odontosyllis octodentata Treadwell (Annelida) off La Parguera, P.R. Caribb J Sci 5, 103-107 (1965).

19. Mitani, Y. et al. Efficient production of glycosylated Cypridina luciferase using plant cells. Protein Expr. Purif. 133, $102-109$ (2017).

20. Yasuno, R., Mitani, Y. \& Ohmiya, Y. Effects of N-Glycosylation deletion on Cypridina luciferase activity. Photochem. Photobiol. 94, 338-342 (2018)

21. Futahashi, R. Molecular Mechanisms Underlying Color Vision and Color Formation in Dragonflies. Diversity and Evolution of Butterfly Wing Patterns: An Integrative Approach, eds Sekimura, T, Nijhout, H. F. (Springer, Singapore), pp 303-321 (2017).

22. Grabherr, M. G. et al. Full-length transcriptome assembly from RNA-Seq data without a reference genome. Nat Biotechnol. 29, 644-652 (2011).

23. Kinjo, S. et al. Maser: one-stop platform for NGS big data from analysis to visualization. Database (Oxford). 2018 Jan 1;2018, https:// doi.org/10.1093/database/bay027 (2018).

24. Futahashi, R. et al. Extraordinay diversity of visual opsin genes in dragonflies. Proc. Natl. Acad. Sci. USA 112, E1247-1256 (2015).

25. Li, H. Aligning sequence reads, clone sequences and assembly contigs with BWA-MEM. arXiv:1303.3997 [q-bio.GN] (2013).

26. Nielsen, H. Predicting secretory proteins with SignalP. Methods Mol. Biol. 1611, 59-73 (2017).

27. Kumar, S., Stecher, G. \& Tamura, K. MEGA7: molecular evolutionary genetics analysis version 7.0 for bigger datasets. Mol. Biol. Evol. 33, 1870-1874 (2016).

28. Tamura, K. \& Nei, M. Estimation of the number of nucleotide substitutions in the control region of mitochondrial DNA in humans and chimpanzees. Mol. Biol. Evol. 10, 512-526 (1993).

\section{Acknowledgements}

We are very grateful to people in Isla Magueyes laboratory, university of Puerto Rico, Emily Ellis (UCSB), and Niko Nensley (UCSB) for assistance with collecting animals. This work was partially supported by JSPS KAKENHI Grant Numbers 26560440 and 16K01929 (to Y.M.).

\section{Author Contributions}

Y.M. conducted the experiments using natural animals. R.Y. conducted the mammalian expression experiments. R.F. conducted the RNA-Seq and informatics analysis. T.H.O. organized the animal collection. Y.M. and Y.O. wrote and all the authors modified the paper.

\section{Additional Information}

Competing Interests: The authors declare no competing interests.

Publisher's note: Springer Nature remains neutral with regard to jurisdictional claims in published maps and institutional affiliations.

Open Access This article is licensed under a Creative Commons Attribution 4.0 International License, which permits use, sharing, adaptation, distribution and reproduction in any medium or format, as long as you give appropriate credit to the original author(s) and the source, provide a link to the Creative Commons license, and indicate if changes were made. The images or other third party material in this article are included in the article's Creative Commons license, unless indicated otherwise in a credit line to the material. If material is not included in the article's Creative Commons license and your intended use is not permitted by statutory regulation or exceeds the permitted use, you will need to obtain permission directly from the copyright holder. To view a copy of this license, visit http://creativecommons.org/licenses/by/4.0/.

(C) The Author(s) 2019 